\section{PENITENTIAR Y}

AT

\section{MILBANK.}

Extract from the Report of the Select Committee of the House of Commons, appointed to inquire into the Present State of the Penitentiary at Milbank.

Your Committee felt it their duty to inquire not only into the cause of the disease so long prevalent, but also into the medical treatment of it, and more particularly so in consequence of a difference of opinion being held upon this important subject by the surgeons and physicians they called before them. They did not, however, do this from their entertaining the least suspicion of the talent, judgment, and skill of the medical officers of the establishment, Drs. Roget and Latham; but when a contrariety of opinion was held upon a subject, in which the lives of hundreds of human beings might ultimately depend, who bad no choice but to submit to the treatment which their medical advisers might prescribe, your Committee considered themselves imperiously called upon to refer the subject to the best medical authorities the country could produce; accordingly, a deputation from the College of Physicians visited the Penitentiary, and their Report, which is here subjoined, sets, in the opinion of your Committee, the question at rest, and fully confirms the propriety of the practice of Drs. Roget and Latham.

(Copy.) "Whitehall, June 23, 1823.

"Sir,-In consequence of the - illness which has long prevailed at the Penitentiary, and the differ-s ence of opinion which has been expressed by medical men of considerable eminence, with respect to the causes of the disorder, and the nature of the remedies which it is proper to apply, I am induced to request that you will bring the subject under the consideration of the College of Phy sicians, and that you will have the goodness to move the appointment of a Committee for the purpose of visiting the Penitentiary, and of reporting to me their opinion upon the nature of the disorder which prevails in that Establishment, and upon the probable efficacy of the present course of medical treatment.-I have, \&c. (Signed)" "R. PEel."

"Sir H. Halford, Bart, \&c, \&c. \&c."

(Copy.)

"In compliance with the request of the Right Hon. Secretary of State for the Home Department, we, the undersigned members of a Committee, appointed by the College of Physicians, have visited the Penitentiary at Milbank, examined the state of the patients there, heard the accounts given by the medical attendants; and do report upon the two questions submitted to our investigation, as follows :-

"From the testimony of the medical officers, compared with the details given uniformly by the patients themselves, of the former stages of the disease prevalent amongst them, that the disorder has borne a dysenteric character. But we have to observe, that the patients are now far advanced towards recovery, and that the severer synotoms which distinguish dysentery, prevail no longer. Many, however, still continue ill of a milder complaint of the bowels.Upon the second question we report, that the treatment by mercury, adopted in this disease, appears to have been very successful.
(Signed) "HENRY HALFORD, President of the College. "HENRY AINSLIE. “EDWARD ASH. "W. G. MATON. "THOMAS TURNER. " PELHAM WARREN,"

"College of Physicians, June 27th, 1823!" 
On the 15th of May, the annexed List was given in by Dr. Roget, Physician to the Establishment:Prisoners under Medical Treatment on the 15 th of May.

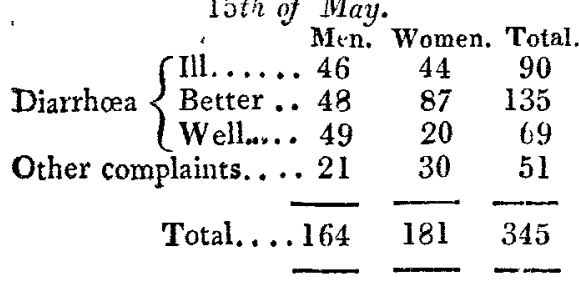

May 23, 1823.

Men. Women. Total.

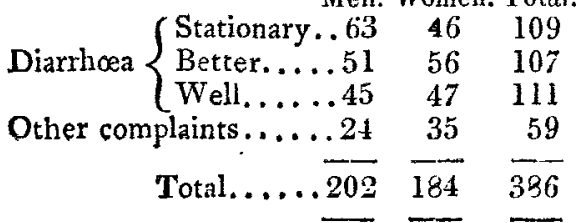

June 11, 1823.

Men. Wumen. Total.

Diarrhoa $\left\{\begin{array}{llll}\text { Stationary } & 73 & 35 & 108 \\ \text { Improving } & 86 & 38 & 124 \\ \text { Well.... } & 82 & 88 & 170 \\ \text { Other complaints.... } & \mathbf{2 4} & 28 & \mathbf{5 2} \\ \text { Total...... } & \underline{265} & \underline{\mathbf{1 8 9}} & \overline{\mathbf{4 5 4}}\end{array}\right.$

Since this Reportwas drawn up, a return of the prisoners under medical treatment on the $3 d$ July 1823, has been given in to the Committee; by which it appears that the disease is rapidly on the decline; the sick, who are considered as stationary, being reduced from 108 to 39.

Prisoners under Medical Treatment, $3 \mathrm{~d}$ July, 1823.

Men. Women, Total.

Stationary........ I7 $22 \quad 39$

Convalescent....... $70 \quad 37 \quad 107$

Well........... $179 \quad 83 \quad 262$

III of other diseases. . $8 \quad 22 \quad 30$

Total.... $\overline{274} \overline{164} \overline{438}$

The following are Extracts from the Evidence.

Dr. Roget examined.

Do you not think that the moral causes had a very great influence in creating the complaint, as well as the physical ones?-I think they had a considerable infuence.
Will you statewhat those causes are, which are desiornated generally under the name of moral causes? -General depression of mind from the loss of liberty, and privations of diflerent kinds consequent upon that loss ; despondency generally.

Do you think that the long terms of imprisonment to which persons are sentenced, may be considered as one of the most leading of those moral causes ?-I think so.

And of course operating in a stronger degree in this prison than any other, from the length of the terms being so much greater?Certainly.

When you visited the Penitentiary, you of course saw Dr. Hutchison, the principal medical officer? -Certainly.

Did the patients in the hospital appear to you to be properly attended to by him?-Yes.

Did his mode of treating the disease, namely, the disease of the scurvy, appear to you to be that which was the best fitted to cure it?-We had not an opportunity of seeing the treatment he adopted, previously to our being called in; and, indeed, there had been but little opportunity for the employment of any medical treatment.

In point of principle, was not your treatment nearly the same, or differing in a very trifling degree, with the treatment he adopted?We adopted the same treatment, as far as the zcurvy is concerned, that he had recommended.

In what was the difference in your practice, as to any other complaint? - The diarrhoea we did not treat in the same mode.

Was every information given to you by Dr. Hutchison, which you thought fit to ask him, and every facility afforded to you by him?Perfectly so.

Had you any conversation with him relative to the drooping state of convicts in the early part of the winter?-We undoubtedly conversed with him on all those subjects.

Did any of the Committee ex- 
press to you any doubt as to the medical treatment of Dr. Hutchison, $\mathrm{cr}$ any unfavourable opinion of his conduct as the medical officer of the establishment?-Not the smallest.

Do you think that the diet, which the prisoners receive, is not sufficient for a person confined only for six months? - It would appear so, from what we have seen of the Penitentiary.

Supposing it is found, in other prisons, to be quite sufficient for a period of six or twelve months, why should it not, in the Penitentiary, be also sufficient?-I am unable to explain the reason, but such is the fact.

You state that the diet is not sufficient for those who are employed in bard labour, and that that has been in a great measure the cause of the disease which prevails; how comes it then that the disease appears to have commenced, and to have been to a greater degree among those that were not employed at all ?-We found it difficult to account for that, unless by taking into account the effect of the greater cold to which they are exposed during the night in the sleeping cells.

You know what the tread-mill is ; do you consider that it is calculated to injure the individuals at all who are employed in that way? -Reasoning without experience, I should not think it would injure the prisoners.

(To Dr. P. M. Latham.)-Is that your opinion?-Certainly ; and as far as medical opinion has been ascertained upon this subject, I understand there is only the objection of one medical man to the employment of the tread-mill, and he says it is calculated te produce hernia.

Are you of that opinion?-I have not seen the tread-mill myself.

(To Dr. Roget.) - Are you acquainted with the gaol of Newgate?-I am not.

Or any other large prison in the metropolis?-No.
Are you of opinion, that if prisoners in any other prison of the metropolis not near the river Thames; for example, in the prisons of the city of London or Cold Bath Fields ; had been confined to the same diet as has been practised at the Penitentiary, and managed precisely in the same manner, they would have been liable to the same sort of complaints? I I think they would.

Do you happen to know whether there is any such complaint in the prison at Cold Bath Fields ?-I do not.

Had you had any previous experience of the disease called sea scnrvy, before you went into the Penitentiary? - All the cases of scurvy I have seen, have been single, and occasional cases of scurvy, such as occur in the London hospitals.

(Dr. Roget.)-My experience is of the same kind; I have seen occasional cases, in workhouses and hospitals.

Sea scurvy ;-(Dr.P. M. Latham.) It is found there is no distinction : that the disease known by the name of sea scurvy, is in fact amphibious.

(To Dr. Roget.) -Are you not in the habit of attending one of the dispensaries?-I am ; I have been physician to the Northern Dispensary for the last thirteen years.

Whenever there is low diet and diminished food, is not that disease, whether on board ship or on shore, one of common occurrence? - (Dr. P. M. Latham.) I do not know that it is one of common occurence on shore; it is considered that any causes which are calculated to depress, may possibly produce this disease among many others.

Do you know, as a medical fact, that in besieged towns it is a disease of common occurrence, where inhabitants are straitened for food? -Yes.

[To be concluded ins our next.] 